\title{
Use of pain threshold reports to satisfy social needs
}

\author{
Geoff MacDonald PhD
}

G MacDonald. Use of pain threshold reports to satisfy social needs. Pain Res Manage 2008;13(4):309-319.

OBJECTIVE: To examine the hypothesis that experimental threats to social belongingness, interacting with individual differences in attachment security, cause modification of pain threshold reports by individuals who report high pain thresholds at baseline.

METHODS: In each of three studies, baseline pain threshold and tolerance were assessed in response to a pain task (cold pressor pain in Studies 1 and 2, finger pressure pain in Study 3). Participants then completed a measure of attachment security and were randomly assigned to a social exclusion or control condition (exclusion from a computer game in Study 1, recalling past rejection experiences in Studies 2 and 3). The pain task was administered again to examine the effects on pain threshold and tolerance.

RESULTS: Those with high anxious attachment and high baseline pain thresholds reported higher postmanipulation pain thresholds in the exclusion conditions than in the control conditions. Those with low anxious attachment and high baseline pain thresholds reported lower postmanipulation pain thresholds in the exclusion conditions than in the control conditions. No differences were found for pain tolerance.

CONCLUSIONS: Across studies, results suggested that postmanipulation pain threshold reports of individuals with high baseline pain thresholds were particularly responsive to social exclusion. The form of the response was dependent on the level of anxious attachment. The present studies provide evidence that variance in pain threshold reports not accounted for by pain intensity may reflect the use of pain reports to satisfy social needs. This work also suggests that baseline measures of pain thresholds may, in interaction with psychological variables, have predictive power beyond serving as a control variable.

Key Words: Attachment; Pain threshold; Social exclusion; Social pain

E xperimental studies of pain incorporate a diverse range of measures to capture painful experiences. Three common measures of pain in the experimental context are pain threshold, pain tolerance and subjective discomfort (1). Although these three measures are correlated, even a cursory read of the pain literature makes clear that they are not equally influenced by a range of measured and manipulated variables. The present research attempts to clarify some of the unique aspects of pain threshold reports by considering reports of pain in the laboratory as a form of pain behaviour, or an act of communication of pain and suffering $(2,3)$. Pain threshold is measured by asking participants to report the time point or intensity at which an

\section{L'utilisation des déclarations des seuils de la douleur pour répondre à des besoins sociaux}

BUT : L'étude avait pour but de vérifier l'hypothèse selon laquelle les expériences susceptibles de menacer l'appartenance sociale et entrant en interaction avec les différences individuelles en ce qui concerne la solidité de l'attachement modifient les déclarations des seuils de la douleur chez les personnes qui font état de seuils élevés de la douleur au départ. MÉTHODE : Dans chacune des trois études, il y a eu une évaluation du seuil initial de la douleur et de la tolérance avant une provocation expérimentale de la douleur (épreuve au froid dans les $1^{\text {re }}$ et $2^{\mathrm{e}}$ études; épreuve de la pression du doigt dans la $3^{\mathrm{e}}$ étude). Les participants ont alors fourni une mesure de la solidité de l'attachement, puis ont été dirigés au hasard vers le groupe d'exclusion sociale ou vers le groupe de condition témoin (exclusion d'un jeu à l'ordinateur dans la $1^{\text {re }}$ étude; rappel d'expériences de rejet dans le passé dans les $2^{\mathrm{e}}$ et $3^{\mathrm{e}}$ études). Nous avons ensuite répété l'expérience de la douleur afin de vérifier ses effets sur les seuils de la douleur et la tolérance.

RÉSULTATS : Les personnes qui connaissaient un degré élevé d'anxiété lié à l'attachement et des seuils élevés de la douleur au départ ont fait état de seuils postexpérimentaux encore plus élevés lorsqu'elles étaient en situation d'exclusion. Celles qui connaissaient un faible degré d'anxiété lié à l'attachement mais des seuils élevés de la douleur au départ ont fait état de seuils postexpérimentaux moins élevés lorsqu'elles étaient en situation d'exclusion. Aucune différence n'a été observée en ce qui concerne la tolérance à la douleur.

CONCLUSIONS : D'après les résultats obtenus dans l'ensemble des études, il semblerait que les déclarations postexpérimentales des seuils de la douleur chez les personnes connaissant des seuils élevés de la douleur au départ reflètent une forte sensibilité à l'exclusion sociale, et la forme de la réaction dépendait du degré d'anxiété lié à l'attachement. Les présentes études montrent que les variations observées dans les déclarations des seuils de la douleur non pondérées par l'intensité de la douleur peuvent refléter une utilisation des déclarations de la douleur pour répondre à des besoins sociaux. Le travail de recherche donne également à penser que la mesure des seuils initiaux de la douleur, en interaction avec des variables psychologiques, peut avoir une puissance prédictive, outre sa fonction de variable de contrôle.

aversive stimulus is experienced as being painful. Pain tolerance is measured by asking participants to stop a painful stimulus when the pain is no longer bearable. Discomfort ratings involve subjective evaluations of the degree of pain experienced during a pain task. Although measures of pain threshold have been described as reasonably reliable (4), their validity as a marker of the intensity of experienced pain has been questioned. Chapman et al (1), in a review of pain assessment techniques, argued that pain threshold measures produce relatively inconsistent results and are subject to influence from placebo effects, expectancy, instructional set and other psychological factors. Indeed, pain threshold does not consistently increase 
in response to proven analgesics (5). Despite these concerns, there is some evidence for the predictive validity of pain threshold reports $(6,7)$. The question is, what does the construct of pain threshold represent?

To determine the meaning of the unexplained but seemingly reliable variance in pain threshold, a measure that more closely tracks pain intensity is needed for comparison and control. Pain tolerance is an easily obtained measure that may suit this purpose. The relative validity of pain tolerance as a marker of pain intensity is attested to by its responsiveness to known analgesics (5). Chapman et al (1) concluded that "tolerance methods approximate clinical acute pain states better than most laboratory stimulation procedures." Therefore, one basis for examining the meaning of pain threshold reports may be tracking discrepancies between pain tolerance (as a marker of pain intensity) and pain threshold. Conditions that influence pain tolerance and pain threshold differently (8-14) may provide insight into factors other than pain intensity that drive pain threshold reports.

One potentially important factor in examining the meaning of pain threshold reports is that such reports may be uniquely vulnerable to subjective distortion. Pain tolerance measures should be less subject to distortion than self-reports of pain threshold because of the extent to which they rely on nonverbal expression of pain (15). Thus, shifts in pain threshold not accompanied by similar shifts in pain tolerance (or vice-versa) may indicate an influence on pain sensitivity reports other than pain intensity. Similarly, the variance remaining in pain threshold reports after controlling for pain tolerance scores may reflect, at least in part, subjective distortion in reports of pain sensitivity.

What might motivate such distortion of pain reports? Pain threshold is not reliably influenced by genetics and, thus, explanations of this measure's meaning must focus on environmental factors (16). One nearly ubiquitous and highly important environmental influence is social context (17). With reference to pain research, Kállai et al (14) noted, "the report of pain virtually always takes place in the presence of another person." In this interpersonal context, pain reports may take on a social communication function. Some participants may believe that a pain task allows them to communicate interpersonal qualities such as stoicism, toughness or vulnerability (2). Taken together, this analysis suggests that those who report high pain thresholds (especially while controlling for pain tolerance) may be individuals who subjectively distort pain reports because they believe such reports convey important social meaning. As a result, postbaseline pain threshold reports may be distorted to satisfy salient social concerns, such as belongingness needs.

Previous research examining the predictive power of baseline pain thresholds in the context of reminders of mortality supports the notion that those who report high pain thresholds at baseline use subsequent pain threshold reports to satisfy psychological needs. Reminders of mortality have been shown to motivate individuals to strive for self-esteem and validation of their personal worldviews as compensation for anxiety about death (18). In one study (Study 3 of an unpublished manuscript), participants with high baseline pain thresholds, who were randomly assigned to a personal mortality reminder condition, reported higher postmanipulation pain thresholds than comparable participants assigned to a control condition. Those with low pain thresholds at baseline did not differ across the conditions. This pattern of results held after controlling for both baseline and postmanipulation pain tolerance simultaneously. One interpretation of these data is that individuals who attached personal meaning to pain reports at baseline (ie, those with high baseline pain thresholds) and who had been reminded of death were particularly motivated to appear to be without pain in the postmanipulation pain task. Demonstration of imperviousness to pain may have provided relief from death anxiety by providing a sense of invulnerability to physical threats (potentially a means for feeling less vulnerable to death in the short term and/or an important aspect of the worldview of those who value low pain sensitivity). Importantly, no effects across experimental conditions were evident for postmanipulation pain tolerance, suggesting that the manipulation influenced subjective reports rather than degree of pain intensity. Furthermore, these findings were not replicated by substituting baseline pain tolerance or sex for baseline pain threshold as an independent variable in the analyses. Overall, these data suggested that pain thresholds were manipulated to satisfy psychological needs arising from reminders of mortality.

The present research more specifically examines the hypothesis that pain threshold reports can be used to satisfy the psychological need for belongingness. If pain threshold reports are seen by those with high baseline pain thresholds as serving a social communication function, then conditions that heighten belongingness needs should lead to predictable changes in subsequent pain threshold reports. One experience that has been shown to increase the need felt for belongingness is social exclusion. Individuals randomly assigned to experience or recall social exclusion have been shown to demonstrate increased motivation for interpersonal connection (19) and heightened attention to social information (20). How an individual responds to the desire for connection, when spurred by exclusion, is influenced by the individual's level of interpersonal security in a fashion that is particularly relevant in the context of pain research.

Expressions of emotional distress, including reports of pain, provide a signal of vulnerability that can motivate caregiving responses by others (21). Although useful for recruiting social support, such expressions of vulnerability also entail a degree of social risk. Expressions of emotional distress can be met by negative forms of support, such as interpersonal rejection, that exacerbate rather than reduce the distress (21). As a result, individuals withhold signals of vulnerability unless they are reasonably confident their distress will be met with support (22). The perceived consequences of turning to others for social support, therefore, may influence the expression of pain. Research on attachment theory has shown stable individual differences in such expectations of support that fall along two dimensions (for reviews, see 23,24). Those high on the dimension of anxious attachment tend to be concerned about the possibility of further social harm resulting from calls for support because they tend to doubt their acceptability to others. As a result, anxiously attached individuals are hypervigilant for signs of rejection. Although these individuals strongly desire support and validation from others, they also fear that pursuing support will lead to rejection. Those high on the dimension of avoidant attachment doubt the availability of support because they view others as unreliable. Avoidantly attached individuals tend to be uncomfortable turning to others for support because they do not expect such calls for support to be helpful in relieving distress. In general, those who feel more secure 
about the quality of available support respond to emotional distress by signalling vulnerability, confident this will lead to caregiving responses (22). Those who are less secure in the availability of quality support respond in a more defensive fashion, withholding expressions of vulnerability to reduce the risk of further social harm or disappointing support provision.

This analysis leads to a set of hypotheses regarding pain threshold reports following a social exclusion experience. First, those who report higher pain thresholds at baseline (ie, before exclusion) should be more likely to view subsequent pain reports as having a socially expressive function. Thus, when belongingness needs are heightened by social exclusion, those with high baseline pain thresholds should seek to resolve their social needs through subsequent pain threshold performance, more so than those with low baseline pain thresholds. Second, the performance of those with high baseline pain thresholds should depend on their level of attachment security. Those with low levels of security should be hesitant to reveal vulnerability and should thus report relatively high postmanipulation pain thresholds. Such a display of invulnerability should help ease concerns about rejection for insecure individuals. Those with high levels of security should be comfortable with vulnerability following exclusion and, thus, should report relatively low pain thresholds. Low pain threshold reports may be used by secure individuals as a means of recruiting care and concern. Finally, these effects should be found for pain threshold, but not for subjective discomfort ratings or pain tolerance. Statistically, this reasoning leads to the prediction of a threevariable interaction (social exclusion by baseline pain threshold by attachment insecurity) for postbaseline measures of pain threshold. No specific hypotheses for the most relevant type of attachment insecurity (anxious or avoidant) were developed.

These hypotheses were tested across three studies in the present research. In all studies, baseline pain sensitivity measures were taken. Participants completed a series of individual difference questionnaires, and were then randomly assigned to a social exclusion or control condition. The manipulation was followed by the key dependent measures - postmanipulation measures of pain sensitivity.

\section{STUDY 1 METHODS}

\section{Participants}

Participants were drawn from the University of Queensland introductory psychology participant pool and received one course credit in exchange for participation. A total of 88 individuals participated (72 women, 16 men).

\section{Procedure}

Participants arrived at the lab individually, were greeted by a female experimenter and were told the study focused on personality and physical discomfort. The experimenter noted that, in part, the study was examining the relation between visualization tendencies and experiences of pain. Thus, the procedure would include a visualization exercise in which they would play a computer ball toss game with other participants while imagining the game taking place in real life. After informed consent was obtained, baseline measures of pain sensitivity were taken. Participants were asked to place their nondominant arm in a container filled with water cooled to $1^{\circ} \mathrm{C}$ for as long as they could. During this time, three measures of pain sensitivity were taken (threshold, discomfort and tolerance). After $4 \mathrm{~min}$, if a participant had not yet removed her or his arm from the cold water, the cold pressor task was ended (participants were not informed of the time limit before the task). Participants were then asked to complete a questionnaire package including measures of self-esteem and attachment. The final page of this package included a bogus visualization tendencies questionnaire meant to enhance the cover story. Next, they were asked to engage in the visualization exercise, which was, in fact, the social exclusion manipulation (ie, Cyberball; 25). Participants sat at a computer and played a video ball toss game with what they believed were three other human players. Participants were randomly assigned to either the inclusion or the exclusion condition, with the experimenter blind to condition. In the inclusion condition, participants received a ball toss on 10 of the 40 total throws, but in the exclusion condition, participants received the ball only twice in 40 throws. Following the Cyberball game, participants underwent a second cold pressor task during which measures of pain sensitivity were again taken. Participants then completed a manipulation check questionnaire and a mood measure. Finally, participants were thanked and carefully debriefed. All procedures described in this paper were approved by the University of Queensland Behavioural and Social Science Ethical Review Committee.

\section{Measures}

Pain threshold: Participants were asked to indicate at what point they began to feel pain after placing their arm in the cold water. The number of seconds taken to indicate first pain sensation after immersion in the water was recorded as the pain threshold.

Discomfort: Participants were asked to indicate to the researcher, at $20 \mathrm{~s}$ intervals, the amount of discomfort they were feeling at the time on a 101 -point scale $(0=$ none at all to $100=$ as bad as can be imagined). Participants' ratings for the first $40 \mathrm{~s}$ (ie, the first two ratings) were averaged to form a measure of discomfort (Cronbach's $\alpha=0.94$ premanipulation, Cronbach's $\alpha=0.94$ postmanipulation). Ratings from two time points were included to increase the reliability of the measure. Further ratings were not included because participant attrition limited the data points available.

Pain tolerance: When participants removed their arm from the cold water, the number of seconds elapsed after immersion in the water was recorded as pain tolerance. If participants persisted to the end of the task, 4 min was recorded as their time. Ethically, it would not be appropriate to test true pain tolerance by asking all participants to endure pain to the full limit of their tolerance. Thus, most research, including the present studies, places an upper time limit on pain tasks. Although this measure may be more accurately termed 'behavioural pain tolerance', the present paper uses the term 'pain tolerance' as a shorthand.

Attachment Style Questionnaire (ASQ; 26): The ASQ is a 40-item fixed-choice questionnaire that measures the two dimensions underlying adult attachment. Anxious attachment is measured with 13 items related to feelings of acceptability (eg, "I find that others are reluctant to get as close as I would like"), Cronbach's $\alpha=0.83$. Avoidant attachment is measured with 16 items related to the tendency to maintain interpersonal distance (eg, "I prefer to depend on myself rather than other people”), Cronbach's $\alpha=0.89$. Answers to ASQ items were given on a six-point scale ( 1 = totally disagree to $6=$ totally agree). The ASQ scales have been shown to 
TABLE 1

Untransformed pain task mean scores for retained participants in Study 1

\begin{tabular}{lcc}
\hline & Inclusion & Exclusion \\
\hline Baseline pain threshold & $16.34 \pm 8.98$ & $16.02 \pm 12.90$ \\
& $(n=33)$ & $(n=30)$ \\
Postmanipulation pain & $23.86 \pm 29.34$ & $22.65 \pm 33.81$ \\
threshold & $(n=33)$ & $(n=30)$ \\
Baseline discomfort & $59.94 \pm 20.51$ & $66.13 \pm 22.34$ \\
& $(n=24)$ & $(n=26)$ \\
Postmanipulation discomfort & $53.40 \pm 27.11$ & $66.11 \pm 25.97$ \\
& $(n=24)$ & $(n=26)$ \\
Baseline pain tolerance & $118.34 \pm 77.94$ & $107.13 \pm 70.06$ \\
& $(n=33)$ & $(n=30)$ \\
Postmanipulation pain & $125.47 \pm 82.91$ & $112.99 \pm 82.90$ \\
tolerance & $(n=33)$ & $(n=30)$ \\
\hline
\end{tabular}

Results are presented as mean $\pm S D$, with sample size below in brackets. Pain threshold and tolerance scores can range from 0 s to 240 s; discomfort scores can range from 0 to 100

TABLE 2

Correlations between premanipulation variables for Study 1

\begin{tabular}{lcccc}
\hline & $\begin{array}{c}\text { Pain } \\
\text { threshold }\end{array}$ & Discomfort & $\begin{array}{c}\text { Pain } \\
\text { tolerance }\end{array}$ & $\begin{array}{c}\text { Anxious } \\
\text { attachment }\end{array}$ \\
\hline Discomfort & $-0.404^{\star * *}$ & & & \\
Pain tolerance & $0.295^{\star *}$ & $-0.427^{* * * *}$ & & \\
Anxious attachment & -0.057 & $0.247^{\star *}$ & $-0.203^{*}$ & \\
Avoidant attachment & -0.144 & 0.135 & -0.093 & $0.383^{* * * *}$ \\
\hline
\end{tabular}

${ }^{*} P<0.10,{ }^{* *} P<0.05,{ }^{* * *} P<0.01,{ }^{* * * *} P<0.001$

correlate in a predicted fashion with other established measures of attachment (26). The ASQ focuses on relationships in general rather than romantic relationships, which makes it more appropriate for adolescent and young adult populations, who may have less experience with serious, romantic relationships (27).

Manipulation check: Participants responded to two manipulation check questions regarding the ball toss game. The first question asked participants to estimate the percentage of throws they received. The second question asked participants to respond to the item, "To what extent were you included by the other participants during the game" on a nine-point scale $(1=$ rejected to 9 included $)$.

Mood: The mood scale consisted of eight items assessing the degree to which participants felt a number of positive (eg, calm) and negative (eg, sad) mood states on a nine-point scale ( $1=$ not at all to 9 = very strongly; Cronbach's $\alpha=0.82$ ). Higher scores represent more positive mood.

\section{RESULTS}

The manipulation check revealed that participants in the inclusion condition $(M=37.02)$ reported receiving a significantly higher percentage of throws than those in the exclusion condition $(\mathrm{M}=9.41), t(85)=9.67, \mathrm{P}<0.001$. In addition, those in the inclusion condition $(\mathrm{M}=6.37)$ reported being included in the game to a greater extent than those in the exclusion condition $(\mathrm{M}=2.00), t(85)=14.17, \mathrm{P}<0.001$.

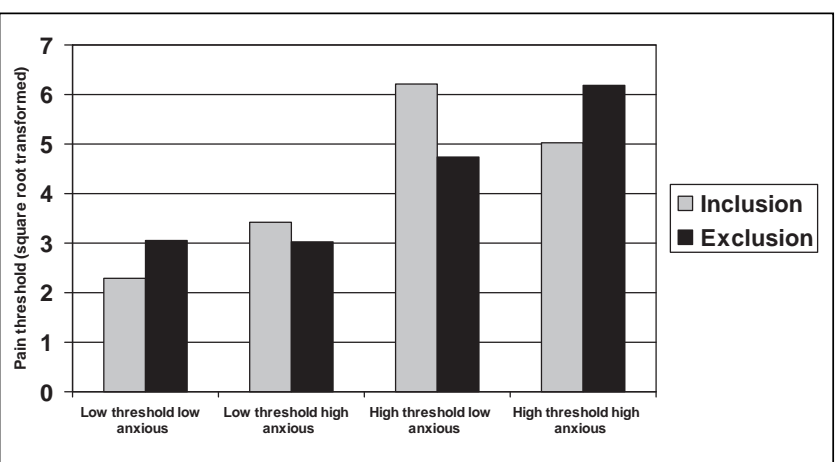

Figure 1) Postmanipulation pain thresholds as a function of baseline pain thresholds, experimental condition and anxious attachment in Study 1

Mean scores for pain threshold, discomfort and pain tolerance are provided in Table 1. Pain threshold data were positively skewed (baseline skew $=2.19$, SES $=0.302$; postmanipulation skew $=3.65$, SES $=0.302$ ) and, thus, a square root transformation was applied. Correlations of all premanipulation variables, reported in Table 2, revealed that neither of the attachment dimensions were significantly related to baseline pain threshold. Examinations of the effects of the social exclusion manipulation, baseline pain threshold, the attachment dimensions and their interactions were conducted using hierarchical multiple regression (28). Thirteen participants (four inclusion, nine exclusion) failed to report pain threshold at baseline and, thus, were not included in these analyses. In step 1, the main effects of the social exclusion manipulation (dummy coded with $0=$ inclusion and 1 = exclusion), anxious attachment, avoidant attachment and baseline pain threshold (all zero-centred) were entered. In step 2, all two-variable interactions were entered; in step 3, all three-variable interactions were entered; and in step 4, the four-variable interaction was entered. To control for the effects of baseline and postmanipulation pain tolerance (as proxy variables for pain intensity), these variables were entered as covariates in step 1 of the analyses of pain threshold and discomfort. Because there were no consistent two-variable interaction effects across studies, interactions at the twovariable level will not be reported in any study for the sake of brevity. These analyses are available on request.

Twenty-two participants failed to report a pain threshold in the postmanipulation pain task (10 inclusion, 12 exclusion). Other participants failed to report a pain threshold at baseline, leaving a final sample of 63 participants. In the first step of the analysis of postmanipulation pain threshold, postmanipulation pain tolerance was a significant predictor $(\beta=0.435, P=0.005$, $\left.R^{2}=0.049\right)$, as was baseline pain threshold $(\beta=0.690, P<0.001$, $\left.\mathrm{R}^{2}=0.405\right)$. No other main effects were found. A significant three-variable interaction between experimental condition, baseline pain threshold and anxious attachment was found, $\beta=0.935, P=0.038, R^{2}=0.022$. To examine the pattern of the interaction, conditional regression equations were calculated separately for participants whose self-esteem and baseline pain threshold scores fell one SD above or below the the mean (28; this strategy is used to examine all interactions across the present studies). As can be seen in Figure 1, low-anxious participants with high baseline pain thresholds reported significantly lower postmanipulation pain thresholds in the exclusion condition than in the inclusion condition, $t(46)=-1.99, \mathrm{P}<0.05$. There was a nonsignificant trend of high-anxiety participants 
with high baseline pain thresholds reporting somewhat higher postmanipulation pain thresholds in the exclusion condition than in the inclusion condition, $t(46)=1.47$, $\mathrm{P}<0.15$. No other simple effects approached even marginal significance. Neither the three-variable interactions or the fourvariable interaction were significant.

Twelve participants withdrew from the pain task before $40 \mathrm{~s}$ elapsed, either at baseline or postmanipulation (six inclusion, six exclusion), leaving a sample of 65 participants for analysis of the measure of discomfort. Baseline discomfort was included as a control variable in step 1 . Baseline discomfort significantly predicted postmanipulation discomfort, $\beta=0.824, \mathrm{P}<0.001$, $\mathrm{R}^{2}=0.444$. Postmanipulation pain tolerance also significantly predicted postmanipulation discomfort, $\beta=-0.364, \mathrm{P}=0.003$, $\mathrm{R}^{2}=0.031$. No other main effects or interactions were significant.

For the analysis of postmanipulation pain tolerance, a main effect of baseline pain tolerance was found, $\beta=0.857, \mathrm{P}<0.001$, $\mathrm{R}^{2}=0.622$. No other main effects or interactions were significant.

For the analysis of mood, a main effect of experimental condition was found, such that those in the exclusion condition experienced a more negative mood than those in the inclusion condition, $\beta=-0.254, P=0.024, R^{2}=0.061$. A main effect of anxious attachment was also found, such that higher anxious attachment was related to a more negative mood, $\beta=-0.330, P=0.009, R^{2}=0.083$. No other main effects or interactions were significant.

\section{DISCUSSION}

The results of Study 1 suggested that individuals who reported higher pain thresholds in the baseline pain task were more likely to adjust their subsequent pain threshold reports across experimental conditions than those who reported low baseline pain thresholds. These results were found while controlling for both baseline and postmanipulation pain tolerance, suggesting that the effects are more attributable to displays of pain than variation in experienced pain intensity. These data are consistent with the hypothesis that those with high baseline pain thresholds use pain threshold reports to regulate social needs.

The reaction of those with high baseline pain thresholds to social exclusion appeared to depend on levels of anxious, but not avoidant, attachment (see General Discussion for consideration of this point). Those with high baseline pain thresholds and low anxious attachment reported significantly lower postmanipulation pain thresholds in the exclusion condition than in the inclusion condition. These participants appeared to respond to exclusion with a display of vulnerability to pain. Conversely, although the trend did not reach significance, those with high baseline pain thresholds and high anxious attachment reported somewhat higher postmanipulation pain thresholds in the exclusion condition than in the inclusion condition. This is consistent with a show of invulnerability to pain, although the weakness of the effect renders its reliability questionable. The exclusion manipulation did not influence participants' reports of discomfort or pain tolerance, suggesting the relatively manipulable nature of pain threshold reports are especially targeted as a means of regulating social needs. Furthermore, baseline pain threshold was unrelated to mood, either alone or in interaction with other variables, suggesting that mood cannot account for these effects.
Study 1, then, provides some support for the argument that pain threshold reports can be used to satisfy social concerns. Although statistical support was weak in the case of those with high anxious attachment, this may be a function of the nature of the control condition. Anxiously attached individuals, who are hypervigilant for cues of rejection, may have subjectively experienced noninclusion even when receiving their fair share of throws (ie, 10 or one-quarter of the throws). That is, watching 30 of 40 throws go to other participants may have led to some feelings of exclusion (note that the manipulation check asked about the degree of inclusion by other players rather than subjective feelings of inclusion). It is possible, then, that anxiously attached individuals in the present study experienced heightened belongingness needs in both the inclusion and exclusion conditions. To more clearly examine the influence of need for belongingness on pain reports, Study 2 incorporated a different experimental manipulation that allowed for a more asocial control experience. Rather than taking part in the Cyberball game, participants were asked to engage in a brief writing task in which they either wrote about the experience of rejection or the experience of watching television. Incorporating a different manipulation allowed not only increased precision, but the opportunity to examine generalizability across different operationalizations of social exclusion.

\section{STUDY 2 METHODS}

\section{Participants}

Participants were drawn from the University of Queensland introductory psychology participant pool and received one course credit in exchange for participation. A total of 50 individuals participated (36 women, 14 men).

\section{Procedure}

The procedure for Study 2 was identical to Study 1 except for the change in experimental manipulation. The Cyberball social exclusion procedure was replaced with a single page at the end of the first questionnaire booklet that was completed between baseline and postmanipulation pain sensitivity measurements. Participants were randomly assigned to respond to one of two sets of brief, open-ended questions about a past experience of either rejection or watching television (adapted from 29). The questions in the exclusion condition read, "Please briefly describe the emotions that the thought of a specific past experience of rejection by an important other arouses in you," and "What happened to you emotionally as you were being rejected and once the important other was gone." The questions in the control condition read, "Please briefly describe the emotions that the thought of watching television arouses in you," and "What happens to you emotionally as you watch television and once you have watched television." The experimenter was blind to condition. The cover story was changed to describe the study as investigating the relation between emotional writing and pain.

\section{Measures}

Pain sensitivity: Measures of pain threshold, discomfort and pain tolerance were identical to Study 1 . Cronbach's $\alpha$ s for the measure of discomfort were 0.96 at baseline and 0.95 postmanipulation.

Questionnaires: The same measures as Study 1 were used. Cronbach's $\alpha$ s for this sample were as follows: anxious attachment, 0.85; avoidant attachment, 0.88; mood, 0.83 . 
TABLE 3

Untransformed pain task mean scores for retained participants in Study 2

\begin{tabular}{lcc}
\hline & Control & Exclusion \\
\hline Baseline pain threshold & $20.24 \pm 19.53$ & $24.48 \pm 31.70$ \\
& $(n=17)$ & $(n=23)$ \\
Postmanipulation pain & $27.44 \pm 28.92$ & $29.41 \pm 29.22$ \\
threshold & $(n=17)$ & $(n=23)$ \\
Baseline discomfort & $65.19 \pm 25.63$ & $67.39 \pm 20.48$ \\
& $(n=13)$ & $(n=23)$ \\
Postmanipulation discomfort & $62.81 \pm 28.57$ & $67.33 \pm 20.68$ \\
& $(n=13)$ & $(n=23)$ \\
Baseline pain tolerance & $125.26 \pm 103.81$ & $101.04 \pm 80.85$ \\
& $(n=17)$ & $(n=23)$ \\
Postmanipulation pain & $124.44 \pm 98.37$ & $109.20 \pm 85.78$ \\
tolerance & $(n=17)$ & $(n=23)$ \\
\hline
\end{tabular}

Results are presented as mean $\pm S D$, with sample size below in brackets. Pain threshold and tolerance scores can range from 0 s to $240 \mathrm{~s}$; discomfort scores can range from 0 to 100

TABLE 4

Correlations between premanipulation variables for Study 2

\begin{tabular}{lcccc}
\hline & $\begin{array}{c}\text { Pain } \\
\text { threshold }\end{array}$ & Discomfort & $\begin{array}{c}\text { Pain } \\
\text { tolerance }\end{array}$ & $\begin{array}{c}\text { Anxious } \\
\text { attachment }\end{array}$ \\
\hline Discomfort & -0.250 & & & \\
Pain tolerance & $0.556^{\star *}$ & $-0.490^{*}$ & & \\
Anxious attachment & -0.135 & 0.164 & -0.178 & \\
Avoidant attachment & 0.038 & -0.203 & 0.098 & $0.378^{*}$ \\
\hline
\end{tabular}

${ }^{*} P<0.01,{ }^{* *} P<0.001$

\section{RESULTS}

Mean scores for the pain task are provided in Table 3. Pain threshold data were again positively skewed (baseline skew $=$ $3.34, \mathrm{SES}=0.374$; postmanipulation skew $=1.55, \mathrm{SES}=0.374$ ) and, thus, a square root transformation was applied. The correlations between all premanipulation variables are listed in Table 4, and show that baseline pain threshold was not significantly related to either of the attachment dimensions. The analysis plan was identical to that of Study 1 . Four participants failed to report a baseline pain threshold (all in the control condition). An additional six participants failed to report a postmanipulation pain threshold (four control, two exclusion), leaving a sample of 40 .

For the analysis of postmanipulation pain threshold, postmanipulation pain tolerance was a significant predictor, $\beta=0.561, P=0.027, R^{2}=0.038$. Baseline pain threshold also significantly predicted postmanipulation pain threshold, $\beta=0.600, P<0.001, R^{2}=0.224$. No other main effects were significant. The experimental condition by baseline pain threshold by anxious attachment interaction was significant, $\beta=0.452, P=0.003, R^{2}=0.042$. As can be seen in Figure 2, participants with high baseline pain thresholds and high anxious attachment reported significantly higher postmanipulation pain thresholds in the exclusion condition than in the control condition, $t(23)=3.85, \mathrm{P}<0.001$. Participants with low baseline pain thresholds and high anxious attachment reported significantly lower pain thresholds in the exclusion condition than in the control condition, $t(23)=-2.66, \mathrm{P}<0.05$. No

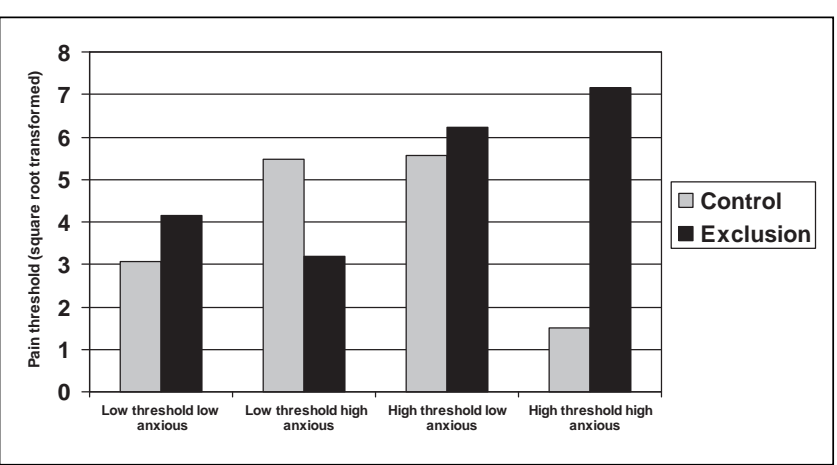

Figure 2) Postmanipulation pain thresholds as a function of baseline pain thresholds, experimental condition and anxious attachment in Study 2

other simple effects across condition were significant. Neither the remaining three-variable interactions or the four-variable interaction were significant.

For the analysis of postmanipulation discomfort, baseline discomfort was included as a covariate in step 1. Fifteen participants withdrew from the pain task before $40 \mathrm{~s}$ elapsed, either at baseline or at postmanipulation (seven control, eight exclusion), leaving a sample of 35 . Baseline discomfort was a significant predictor of postmanipulation discomfort, $\beta=0.785, P<0.001, R^{2}=0.431$. No other main effects were significant, nor were any three- or four-variable interactions.

For the analysis of postmanipulation pain tolerance, baseline pain tolerance was a significant predictor, $\beta=0.859$, $\mathrm{P}<0.001, \mathrm{R}^{2}=0.475$. No other main effects or interactions were significant. For the analysis of mood, a main effect of anxious attachment was found, such that higher anxious attachment was related to a more negative mood, $\beta=-0.366, \mathrm{P}=0.039$, $\mathrm{R}^{2}=0.096$. No other main effects or interactions were significant.

\section{DISCUSSION}

As in Study 1, the key three-variable interaction (experimental condition by baseline pain threshold by anxious attachment) significantly predicted postmanipulation pain threshold scores. This effect was again significant while controlling for baseline and postmanipulation pain tolerance, suggesting the result is difficult to attribute to experienced pain intensity. As with the trend in Study 1, those with high baseline pain thresholds and high anxious attachment reported particularly high postmanipulation pain thresholds in the exclusion condition, relative to the control condition. That this effect is significant when using a more asocial control condition in Study 2 suggests that the small effect in Study 1 may be a result of the control condition raising belongingness concerns for anxiously attached individuals. Of note, postmanipulation pain thresholds reported in the control condition by those with high baseline pain thresholds and high anxious attachment appeared particularly low in the present study. Thus, this result may best be framed as suggesting that those with high baseline pain thresholds and high anxious attachment may not, under normal conditions, be motivated to maintain the appearance of pain insensitivity across trials. It may also be possible that these individuals, as they become more comfortable with the experimental setting, become increasingly motivated to report low pain thresholds to recruit sympathy. Recall that anxiously 
attached individuals experience conflict between fears of rejection and desire for support. Perhaps, for those in the control condition, fears of rejection were more salient early in the unfamiliar laboratory environment, but desire for support became more salient as their sense of comfort increased. Conversely, those who recalled exclusion appeared to have been motivated to continue the appearance of low sensitivity to pain, possibly reflecting continued salience of their rejection fears.

Two differences for the postmanipulation pain threshold measure were evident from Study 1 to Study 2. First, unlike Study 1, those with high baseline pain thresholds and low anxious attachment did not differ across conditions. This suggests that the reactivity to social exclusion of those with high baseline pain thresholds may be limited to those with high anxious attachment. Second, those with low baseline pain thresholds and high anxious attachment reported significantly lower pain thresholds in the exclusion condition than in the control condition in Study 2 only. This finding may reflect some degree of vulnerability display following social exclusion. Because these two effects differed from Study 1, replication in a third study was needed for confidence in their reliability.

As in Study 1, the exclusion manipulation did not appear to have implications for the measure of pain tolerance. This again suggests that the manipulation affected participants' motivation to regulate their appearance of sensitivity to pain, but did not affect their ability to withstand the painful stimulus. In addition, as with Study 1, the results of Study 2 did not appear explainable in terms of changes in mood.

One potential criticism of the results of Study 2 is that the difference across conditions for those with high baseline pain thresholds and high anxious attachment may be due to the effect of the control rather than the exclusion condition. As noted, those in the control condition appeared to report particularly low pain thresholds. Thus, there may be something about thinking about television viewing that causes this effect, rather than something about considering a past rejection. To address this interpretation, writing about television was replaced with writing about examination stress for the control task in Study 3. Another goal of Study 3 was to replicate the effect using a different painful stimulus. It is possible that there is some feature of the cold pressor task that may be necessary for exclusion to affect pain threshold. To address this issue, finger pressure was used as the painful stimulus in Study 3. Finally, a key concern from the first two studies was the relatively high number of participants who failed to report pain thresholds. Two changes were made in Study 3 to avoid this data loss. First, the need for participants to report pain thresholds was emphasized in the instructions. Second, the measure of discomfort was eliminated to reduce any cognitive load that may have distracted participants and caused them to forget the task instructions.

\section{Participants}

\section{STUDY 3 METHODS}

Participants were drawn from the University of Queensland introductory psychology participant pool and received one course credit in exchange for participation. A total of 33 individuals participated ( 21 women, $12 \mathrm{men}$ ), with an average age of 20.76 years. Age data are, unfortunately, not available for Studies 1 and 2. Because all three samples were drawn from the same participant pool (in different semesters, however), age should be approximately equivalent across studies.

\section{Procedure}

Participants arrived at the lab individually, were greeted by a female experimenter and were told the study focused on personality and physical discomfort.

After informed consent was obtained, baseline measures of pain sensitivity were taken. Participants were asked to place the index finger of their nondominant hand in a device that brought constant focused pressure to bear above the knuckle. They were instructed to keep their finger in the device for as long as they could. During this time, measures of pain threshold and pain tolerance were taken. After $4 \mathrm{~min}$, if a participant had not yet removed her or his finger from the device, the task was ended. Participants were not made aware of the time limit before the pain task. Participants then completed the package of questionnaires, including the measures of anxious and avoidant attachment. The last page of this package contained the experimental manipulation. Those randomly assigned to the exclusion condition wrote about a past experience of rejection as in Study 2. Those in the control condition responded to the items "Please briefly describe the emotions that the thought of writing your next important exam arouses in you," and "What do you think will happen to you as you write your next important exam and when you have written your next important exam?" (30). This question was meant to focus participants on a stressful topic to create some equivalence with the stress that may arise from writing about rejection. The experimenter was blind to condition. On completion of the writing task, measures of pain threshold and tolerance were taken. Participants were thanked and carefully debriefed.

\section{Measures}

Pain threshold: Pain threshold was measured as the number of seconds that elapsed before the first pain sensation.

Pain tolerance: Pain tolerance was measured as the number of seconds that elapsed before participants ended the task.

Questionnaires: The same measures as in Studies 1 and 2 were used. Cronbach's $\alpha$ in this sample were as follows: anxious attachment, 0.83; avoidant attachment, 0.78; mood, 0.83 .

\section{RESULTS}

Mean scores for the pain task are provided in Table 5. Pain threshold data were again positively skewed (baseline skew $=$ 1.95 , $\mathrm{SES}=0.409$; postmanipulation skew $=3.56$, $\mathrm{SES}=$ 0.409) and a square-root transformation was applied. The correlations between all premanipulation variables, listed in Table 6, show that baseline pain threshold was not significantly associated with either anxious or avoidant attachment. The analysis strategy for Study 3 was identical to that of Studies 1 and 2 .

No participants failed to report pain threshold at either baseline or postmanipulation. For the analysis of postmanipulation pain threshold, baseline pain threshold was a significant predictor, $\beta=0.461, \mathrm{P}=0.020, \mathrm{R}^{2}=0.158$. No other main effects were found. A significant experimental condition by baseline pain threshold by anxious attachment interaction was found, $\beta=1.427, P=0.011, R^{2}=0.095$. As can be seen in Figure 3, participants with high baseline pain thresholds and high anxious attachment reported significantly higher postmanipulation pain thresholds in the exclusion condition than in the control condition, $t(16)=2.73, \mathrm{P}<0.05$. Participants with high baseline pain thresholds and low anxious attachment reported significantly lower pain thresholds in the exclusion condition than 
TABLE 5

Untransformed pain task mean scores for participants in Study 3

\begin{tabular}{lcc}
\hline & $\begin{array}{c}\text { Control } \\
(\mathbf{n}=\mathbf{1 6})\end{array}$ & $\begin{array}{c}\text { Exclusion } \\
(\mathbf{n}=\mathbf{1 7})\end{array}$ \\
\hline Baseline pain threshold & $24.61 \pm 28.74$ & $35.36 \pm 43.25$ \\
$\begin{array}{l}\text { Postmanipulation pain } \\
\text { threshold }\end{array}$ & $12.48 \pm 10.02$ & $35.82 \pm 48.39$ \\
Baseline pain tolerance & $113.91 \pm 103.28$ & $122.05 \pm 102.82$ \\
$\begin{array}{l}\text { Postmanipulation pain } \\
\text { tolerance }\end{array}$ & $125.26 \pm 105.10$ & $127.77 \pm 98.10$ \\
\hline
\end{tabular}

Results are presented as mean $\pm S D$. Pain threshold and tolerance scores can range from $0 \mathrm{~s}$ to $240 \mathrm{~s}$

TABLE 6

Correlations between premanipulation variables for Study 3

\begin{tabular}{lccc}
\hline & $\begin{array}{c}\text { Pain } \\
\text { threshold }\end{array}$ & $\begin{array}{c}\text { Pain } \\
\text { tolerance }\end{array}$ & $\begin{array}{c}\text { Anxious } \\
\text { attachment }\end{array}$ \\
\hline Pain tolerance & $0.436^{*}$ & & \\
Anxious attachment & 0.072 & -0.159 & \\
Avoidant attachment & 0.053 & -0.288 & 0.232 \\
\hline
\end{tabular}

${ }^{*} P<0.05$

in the control condition, $t(16)=-2.37, \mathrm{P}<0.05$. Participants with low baseline pain thresholds and low anxious attachment reported significantly higher pain thresholds in the exclusion condition than in the control condition, $t(16)=2.40, \mathrm{P}<0.05$. No difference across condition was found for those with low baseline pain thresholds and high anxious attachment. No other significant interactions were found.

For the measure of postmanipulation pain tolerance, a significant main effect of baseline pain tolerance was found, $\beta=0.953, P<0.001, R^{2}=0.634$. No other main effects or interactions approached significance.

For the analysis of mood, a main effect of anxious attachment was found, such that higher anxious attachment was related to a more negative mood, $\beta=-0.573, \mathrm{P}=0.001$, $R^{2}=0.299$. No other main effects or interactions were significant.

\section{DISCUSSION}

As in the first two studies, participants with high baseline pain thresholds and high anxious attachment reported higher postmanipulation pain thresholds in the exclusion condition than in the control condition. The pattern of the data suggests that anxiously attached individuals with high baseline pain thresholds responded to a reminder of exclusion by appearing insensitive to pain. Study 3 replicated this effect using a different painful stimulus, suggesting that the effect is not limited to a particular type of pain. The present study also suggests that the effect cannot be attributed to some peculiarity of the television control condition used in Study 2, because control participants were asked to write about a different topic in the current study a stressful examination experience. As in Study 2, individuals with high baseline pain thresholds and high anxious attachment who were randomly assigned to the control condition appeared to report particularly low postmanipulation pain thresholds. That this pattern was found using two distinctly different control conditions suggests that those with high baseline

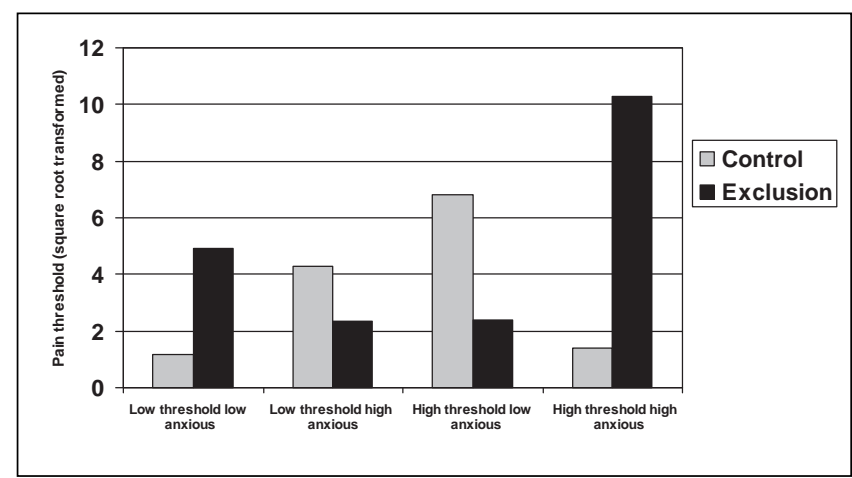

Figure 3) Postmanipulation pain thresholds as a function of baseline pain thresholds, experimental condition and anxious attachment in Study 3

pain thresholds and high anxious attachment may normally shift from a low vulnerability display to a high vulnerability display as time passes, without the presence of social exclusion reminders. As noted previously, this may reflect a change from the salience of rejection concerns to the salience of desire for support. However, those reminded of exclusion may have kept their original rejection concerns salient and reported higher postmanipulation pain thresholds in a display of invulnerability. Given that the manipulation again had no effect on pain tolerance, the effect of exclusion seems to be on the appearance of insensitivity to pain, rather than on a change in experienced pain intensity. In addition, mood again appears unable to explain the results.

Study 3 also showed that individuals with high baseline pain thresholds and low anxious attachment reported significantly lower postmanipulation pain thresholds in the exclusion condition than in the control condition. This effect replicates the data from Study 1, although this pattern was not found in Study 2. Across studies, these data appear to suggest that the postmanipulation pain threshold reports of individuals who report high baseline pain thresholds are particularly reactive to social exclusion, but the specific reaction depends on the level of interpersonal security.

A significant effect was also found for those with low baseline pain thresholds and low anxious attachment, such that higher pain thresholds were reported in the exclusion condition than in the control condition. However, this effect cannot be considered reliable because it only reached significance in Study 3 . Similarly, the effect found in Study 2 - those with low baseline pain thresholds and high anxious attachment reported lower postmanipulation pain thresholds in the exclusion condition than in the control condition - was not replicated in Study 3.

\section{GENERAL DISCUSSION}

The data from the present three studies provide evidence that pain threshold is uniquely susceptible to distortion aimed at satisfying social motivation. In all three studies, random assignment to social exclusion experiences led to changes in reports of pain threshold, but not of pain tolerance. This was true despite the use of different painful stimuli, social exclusion manipulations and control conditions across studies. Combined with similar evidence that reminders of mortality lead to changes in pain threshold but not in pain tolerance reports (unpublished data), a reasonable conclusion seems to be that pain threshold measures are uniquely vulnerable to 
distortion aimed at satisfying psychological needs. Thus, some of the variance in pain threshold measures not accounted for by pain intensity may result from the distortion of pain threshold reports to compensate for psychological threats.

Although the notion that pain thresholds are susceptible to influence from psychological variables other than pain intensity is not new $(1,5)$, the present research provides insight into who is most vulnerable to such distortion and what their motivations may be. Individuals who reported high baseline pain thresholds consistently adjusted subsequent pain threshold reports in a predictable fashion. Across three studies, those with high baseline pain thresholds and high anxious attachment reported particularly high postmanipulation pain thresholds following social exclusion. Anxiously attached individuals are chronically hypervigilant for rejection, but crave support (24). In this light, the high pain thresholds reported only in the social exclusion conditions appear to represent a protective display of low vulnerability in response to the salience of rejection fears. In two of three studies, those with high baseline pain thresholds and low anxious attachment reported lower pain thresholds following social exclusion. Such admission of vulnerability is consistent with the mindset of those who expect supportive responses to signs of distress. That these effects across condition were evident for the reporting of pain threshold, but not pain tolerance, suggests that those with high baseline pain thresholds subjectively altered their pain threshold reports to satisfy relational needs that were heightened by the social exclusion experience.

Understanding the role of pain threshold reports in the satisfaction of psychological needs, such as belongingness, may help clarify some unsettled questions in the pain literature. For example, individuals with eating disorders, such as bulimia nervosa, have been shown to report high pain thresholds in experimental contexts (31). Evidence suggests that these pain threshold reports cannot be accounted for by the effects of malnutrition (32), peripheral neuropathy (33), or physiological markers such as heart rate and blood pressure (31), and are not affected by the administration of opiate antagonists (34). Because high pain threshold reports continue following recovery from bulimia nervosa (35), factors related to the satisfaction of stable psychological needs may be responsible. Some characteristics of those with eating disorders that seem particularly relevant, in light of the current research, include insecurity, struggles with self-control, and denial and distortion in self-reports (36). The high pain threshold reports of those with eating disorders, therefore, may reflect distorted reports that serve to satisfy interpersonal insecurities - by displaying low vulnerability - and needs for an image of high self-control by exhibiting the ability to withstand physical pain.

Similarly, although depressed individuals experience higher levels of clinical pain, a meta-analysis of experimental research shows that depression is associated with higher experimental pain thresholds (37). Pain tolerance results for depressed individuals in experimental contexts are more variable. Given the strong link between depression and higher levels of anxious attachment (38), the high pain threshold reports of depressed individuals may represent a display of invulnerability in what may be seen as a nonsupportive and threatening interpersonal context.

Although no specific predictions were made in the current studies about what form of attachment insecurity may influence pain reports, the present results suggest that anxious attachment plays a more important role than avoidant attachment in influencing reports of pain threshold. This finding is consistent with past research showing anxious, but not avoidant, attachment to predict reports of pain $(8,38)$. In general, avoidantly attached individuals are not emotionally expressive, do not see relationships as a means for regulating distress and do not easily trust others (27). Perhaps, then, these individuals were seemingly unresponsive to the different social circumstances across experimental conditions because expressions of vulnerability to a stranger are not seen by them as relevant to the regulation of pain-related distress. Avoidantly attached individuals may, instead, regulate such distress intrapersonally (eg, by cognitively suppressing it; 24), in a manner that is not affected by the social environment.

The present research differs from past studies examining the effects of social exclusion on pain sensitivity. DeWall and Baumeister (39) showed that individuals randomly assigned to receive feedback suggesting that their lives would be plagued by loneliness demonstrated higher pain thresholds and tolerance relative to those in control conditions. The demonstration of the effect on pain tolerance suggests that this feedback led to a decrease in experienced pain intensity and not just distorted self-reports. In fact, a number of social animals have been shown to respond to social isolation with decreased pain sensitivity (40). However, the present research appears to demonstrate that not all forms of social exclusion lead to such analgesic responses. Perhaps the key difference across the two sets of studies is the strength of the exclusion manipulations. Those in DeWall and Baumeister's research (39) were told their loneliness would be life-long and inevitable, whereas participants in the current research experienced more transient forms of exclusion. More generally, pain researchers should be aware of the growing body of work suggesting that the emotional experience of hurt feelings activates aspects of physical pain affect systems (41).

There are some notable limitations to the current research. Perhaps most importantly, there is no direct evidence that suggests why those with higher baseline pain thresholds appeared more reactive to the social exclusion manipulation. Although I have posited that this effect may be a result of personal meaning invested in reports of pain, no direct measure of pain beliefs was included in the current research. Such beliefs may be difficult to measure. Indeed, these beliefs may not be held consciously and/or may not be formed until participants engage in baseline pain sensitivity tasks. Past research has provided some suggestion that conscious beliefs about pain are not predictive of performance on experimental pain tasks. Edwards and Fillinghim (4) found that responses to the statement, "Pain does not bother me as much as it does most people," were not predictive of pain thresholds or tolerance. However, construction of more reliable, multi-item pain belief measures for future research may provide a better window into the motivations of those with high baseline pain thresholds.

In addition, the one-trial method of pain measurement (ie, completion of the cold pressor or finger pressure task only once to measure pain threshold and tolerance) used in the present research may limit its reliability and may account for some of the variability across studies. Nevertheless, the key threevariable interaction of experimental condition, baseline pain threshold and anxious attachment was evident in all three studies. Furthermore, MacDonald's Study 3 (unpublished data) used a multiple-trial pain measurement approach (ie, obtaining 
pain threshold and tolerance scores from the average of four pain trials at both baseline and postmanipulation), finding that those with high baseline pain thresholds reported higher postmanipulation pain thresholds in the mortality-salient condition relative to the control condition. Thus, more reliable measurement techniques support the conclusion that those with high baseline pain thresholds appear to respond to psychological threats through adjustments of subsequent pain threshold reports. Even so, future research incorporating more reliable measurement techniques and other operationalizations of pain threshold (ie, stimulus intensity levels) would help attest to the generalizability of the current results.

Although the predicted three-variable interaction was replicated across the studies, there was insufficient power to reliably test a potential moderating role for sex. Supplementary analyses (available on request) revealed that controlling for sex did not influence the pattern of results. Furthermore, analyses of the four-variable interaction with the current data provided no evidence of sex as a moderator (all $\mathrm{P}>0.58$ ), although these analyses were underpowered. In the work on mortality salience, MacDonald (unpublished data) similarly found that controlling for the variance accounted for by gender did not change the influence of baseline pain threshold on subsequent pain sensitivity measures, nor did gender significantly interact with baseline pain threshold (although the interaction analyses were similarly underpowered). Thus, the effects of baseline pain threshold do not appear to be attributable to gender. Whether gender interacts with baseline pain threshold in predicting pain reports is a more open question.

Another potential issue is that individual difference measures were taken following baseline pain measures in all three studies. It is possible that the experience of pain measurement may have contaminated responses to the attachment questionnaires. Direct evidence for this argument is limited, because the attachment measures were not significantly related to baseline pain thresholds in any study. Furthermore, attachment theory suggests that individuals' attachment models are activated by the experience of distress (24). Thus, it is arguable that measuring the attachment dimensions following a pain experience may provide a more accurate means of assessing the attachment concerns that arise in the context of acute or chronic pain than those taken before pain trials. However, future research examining any effects of order on the tasks would be of value.

Overall, the present research suggests that some of the reliable, unique variance in pain threshold measures not associated with experienced pain intensity may represent the use of pain reports for the satisfaction of psychological needs, including belongingness. This finding serves as a reminder of the social context of pain research. Past research has shown that participants are less likely to report embarrassing behaviour (as some may perceive the admission of pain) even when a researcher has only potential access to their responses (42). Thus, researchers who wish to control for social influences in experimental pain research may need to devise methods to ensure high degrees of privacy and anonymity for participants. Certainly, reliance on pain threshold reports alone as evidence of reduced pain intensity appears difficult to defend in light of the current research. However, real-life pain is itself a social experience, and the current research provides some insight into factors that may shape the communication of painful states. What is perhaps more novel in the current work is the emphasis on the laboratory as a meaningful social context in which the satisfaction of social needs may be sought. Whereas experienced pain intensity may be an important aspect of maintaining physical integrity, the communication of pain appears important for at least some individuals' psychological integrity.

ACKNOWLEDGEMENTS: The author thanks Patrina Birt and Lisa Golingi for their help with data collection, and Terry Borsook, Jordan Peterson and Patty Pliner for providing feedback on earlier drafts of this manuscript.

AUTHOR'S NOTE: The data from the control conditions in Studies 2 and 3 of the current research also formed the control conditions in Studies 1 and 2 of MacDonald (unpublished data), but in comparison with a different experimental condition (mortality salience).

\section{REFERENCES}

1. Chapman CR, Casey KL, Dubner R, Foley KM, Gracely RH, Reading AE. Pain measurement: An overview. Pain 1985;22:1-31.

2. Hadjistavropoulos T, Craig KD, Fuchs-Lacelle S. Social influences and the communication of pain. In: Hadjistavropoulos T, Craig KD, eds. Pain: Psychological Perspectives. Mahwah: Lawrence Erlbaum, 2004:87-112.

3. Turk DC, Flor H. Pain greater than pain behaviors: The utility and limitations of the pain behavior construct. Pain 1987;31:277-95.

4. Edwards RR, Fillingim RB. Self-reported pain sensitivity: Lack of correlation with pain threshold and tolerance. Eur J Pain 2007;11:594-8.

5. Beecher HK. The measurement of pain; Prototype for the quantitative study of subjective responses. Pharmacol Rev 1957;9:59-209.

6. Pan PH, Coghill R, Houle TT, et al. Multifactorial preoperative predictors for postcesarean section pain and analgesic requirement. Anesthesiology 2006;104:417-25.

7. Edwards RR, Haythornthwaite JA, Tella P, Max MB, Raja S. Basal heat pain thresholds predict opioid analgesia in patients with postherpetic neuralgia. Anesthesiology 2006;104:1243-8.

8. Meredith PJ, Strong J, Feeney JA. The relationship of adult attachment to emotion, catastrophizing, control, threshold and tolerance, in experimentally-induced pain. Pain 2006;120:44-52.

9. Pud D, Eisenberg E, Sprecher E, Rogowski Z, Yarnitsky D. The tridimensional personality theory and pain: Harm avoidance and reward dependence traits correlate with pain perception in healthy volunteers. Eur J Pain 2004;8:31-8.

10. Keogh E, Birkby J. The effect of anxiety sensitivity and gender on the experience of pain. Cogn Emot 1999;13:813-29.

11. Lehofer M, Liebmann PM, Moser M, Schauenstein K. Nervousness and pain sensitivity: I. A positive correlation. Psychiatry Res 1998;79:51-3.

12. Feldner MT, Hekmat H. Perceived control over anxiety-related events as a predictor of pain behaviors in a cold pressor task. J Behav Ther Exp Psychiatry 2001;32:191-202.

13. Willoughby SG, Hailey BJ, Mulkana S, Rowe J. The effect of laboratory-induced depressed mood state on responses to pain. Behav Med 2002;28:23-31.

14. Kállai I, Barke A, Voss U. The effects of experimenter characteristics on pain reports in women and men. Pain 2004;112:142-7.

15. Hadjistavropoulos T, Craig KD. A theoretical framework for understanding self-report and observational measures of pain: A communications model. Behav Res Ther 2002;40:551-70.

16. MacGregor AJ, Griffiths GO, Baker J, Spector TD. Determinants of pressure pain threshold in adult twins: Evidence that shared environmental influences predominate. Pain 1997;73:253-7.

17. Baumeister RF, Leary MR. The need to belong: Desire for interpersonal attachments as a fundamental human motivation. Psychol Bull 1995;117:497-529. 
18. Greenberg J, Solomon S, Pyszczynski T. Terror management theory of self-esteem and cultural worldviews: Empirical assessments and conceptual refinements. In: Zanna M, ed. Advances in Experimental Social Psychology. San Diego: Academic Press, 1997:61-139.

19. Maner JK, DeWall CN, Baumeister RF, Schaller M. Does social exclusion motivate interpersonal reconnection? Resolving the "porcupine problem". J Pers Soc Psychol 2007;92:42-55.

20. Gardiner WL, Pickett CL, Brewer MB. Social exclusion and selective memory: How the need to belong influences memory for social events. Pers Soc Psychol Bull 2000;26:486-96.

21. Collins NL, Guichard AC, Ford MB, et al. Responding to need in intimate relationships: Normative processes and individual differences. In: Mikulincer M. Goodman GS, eds. Dynamics of Romantic Love: Attachment, Caregiving, and Sex. New York: Guildford Press, 2006:149-89.

22. Murray SL, Holmes JG, Collins NL. Optimizing assurance: The risk regulation system in relationships. Psychol Bull 2006;132:641-66.

23. Meredith P, Ownsworth T, Strong J. A review of the evidence linking adult attachment theory and chronic pain: Presenting a conceptual model. Clin Psychol Rev 2008;28:407-29.

24. Shaver PR, Mikulincer M. Attachment-related psychodynamics. Attach Hum Dev 2002;4:133-61.

25. Williams KD, Cheung CK, Choi W. Cyberostracism: Effects of being ignored over the Internet. J Pers Soc Psychol 2000;79:748-62.

26. Feeney JA, Noller P, Hanrahan M. Assessing adult attachment. In: Sperling MB, Berman WH, eds. Attachment in Adults: Clinical and Developmental Perspectives. New York: Guilford Press, 1994:128-52.

27. Mikulincer M, Shaver PR. Attachment in Adulthood: Structure, Dynamics, and Change. New York: Guilford Press, 2007.

28. Aiken LS, West SG. Multiple Regression: Testing and Interpreting Interactions. Newbury Park: Sage Publications, 1991.

29. Rosenblatt A, Greenberg J, Solomon S, et al. Evidence for terror management theory: I. The effects of mortality salience on reactions to those who violate or uphold cultural values. J Pers Soc Psychol 1989;57:681-90.

30. Simon L, Greenberg J, Arndt J, Pyszczynski T, Clement R, Solomon S. Perceived consensus, uniqueness, and terror management:
Compensatory responses to threats to inclusion and distinctiveness following mortality salience. Pers Soc Psychol Bull 1997;23:1055-65

31. Papezová H, Yamamotová A, Uher R. Elevated pain threshold in eating disorders: Physiological and psychological factors. J Psychiatr Res 2005;39:431-8.

32. Lautenbacher S, Pauls AM, Strian F, Pirke KM, Krieg JC. Pain perception in patients with eating disorders. Psychosom Med 1990;52:673-82.

33. Pauls AM, Lautenbacher S, Strian F, Pirke KM, Krieg JC. Assessment of somatosensory indicators of polyneuropathy in patients with eating disorders. Eur Arch Psychiatry Clin Neurosci $1991 ; 2418-12$

34. Lautenbacher S, Pauls AM, Strian F, Pirke KM, Krieg JC. Pain sensitivity in anorexia nervosa and bulimia nervosa. Biol Psychiatry 1991;29:1073-8.

35. Stein D, Kaye WH, Matsunaga $\mathrm{H}$, et al. Pain perception in recovered bulimia nervosa patients. Int J Eat Disord 2003:34:331-6

36. Vitousek K, Manke F. Personality variables and disorders in anorexia nervosa and bulimia nervosa. J Abnorm Psychol 1994;103:137-47.

37. Dickens C, McGowan L, Dale S. Impact of depression on experimental pain perception: A systematic review of the literature with meta-analysis. Psychosom Med 2003;65:369-75.

38. MacDonald G, Kingsbury R. Does physical pain augment anxious attachment? J Soc Pers Relat 2006;23:291-304.

39. DeWall CN, Baumeister RF. Alone but feeling no pain: Effects of social exclusion on physical pain tolerance and pain threshold, affective forecasting, and interpersonal empathy. J Pers Soc Psychol 2006;91:1-15.

40. MacDonald G, Leary MR. Why does social exclusion hurt? The relationship between social and physical pain. Psychol Bull 2005;131:202-23.

41. MacDonald G. Social pain and hurt feelings. In: Corr PJ, Matthews G, eds. Cambridge Handbook of Personality Psychology. Cambridge: Cambridge University Press. (In press)

42. MacDonald G, Nail PR. Attitude change and the public-private attitude distinction. Br J Soc Psychol 2005;44:15-28. 


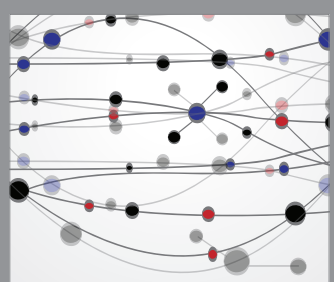

The Scientific World Journal
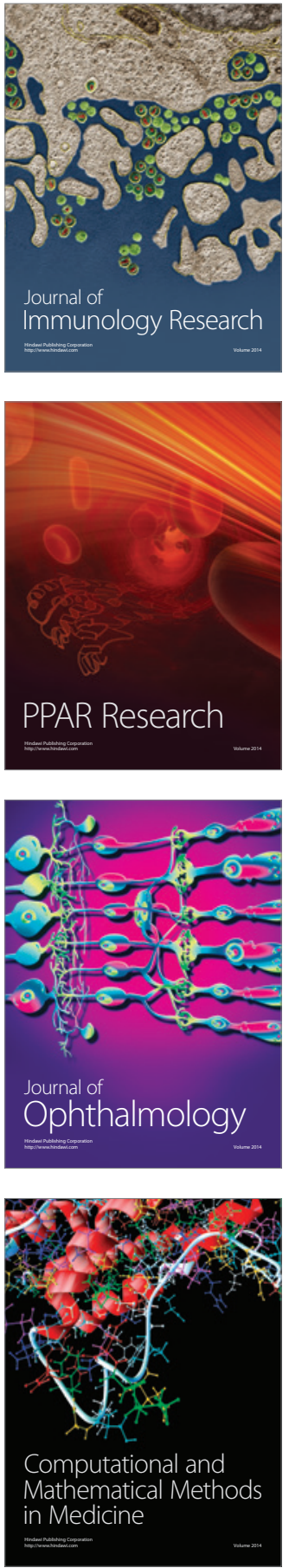

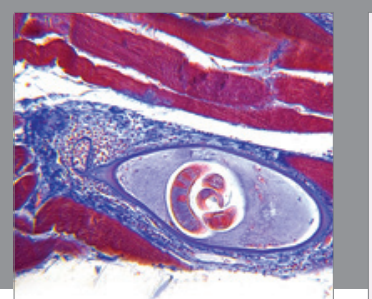

Gastroenterology Research and Practice

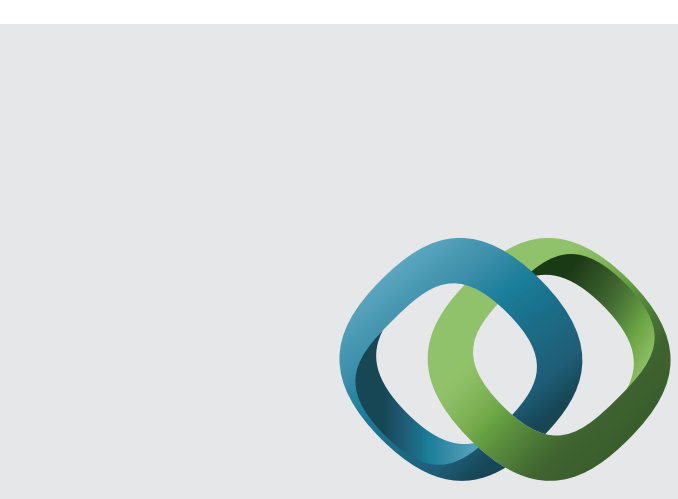

\section{Hindawi}

Submit your manuscripts at

http://www.hindawi.com
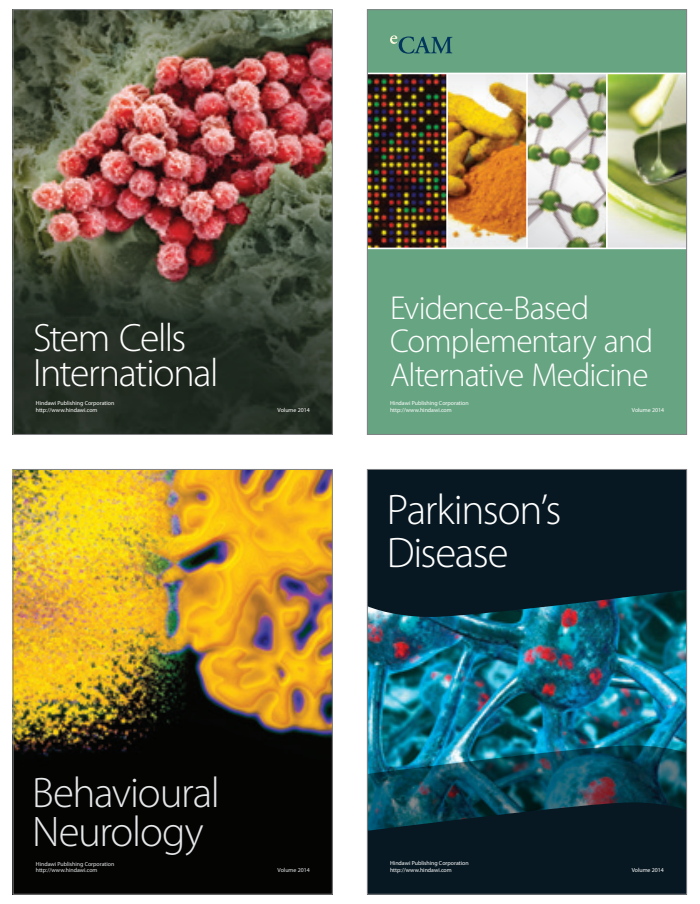
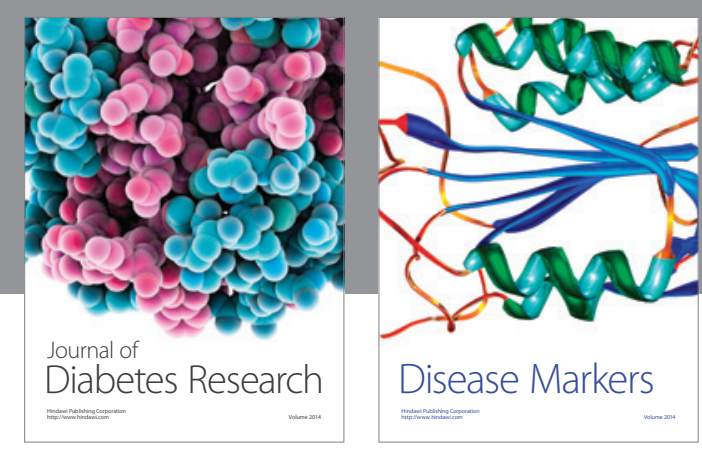

Disease Markers
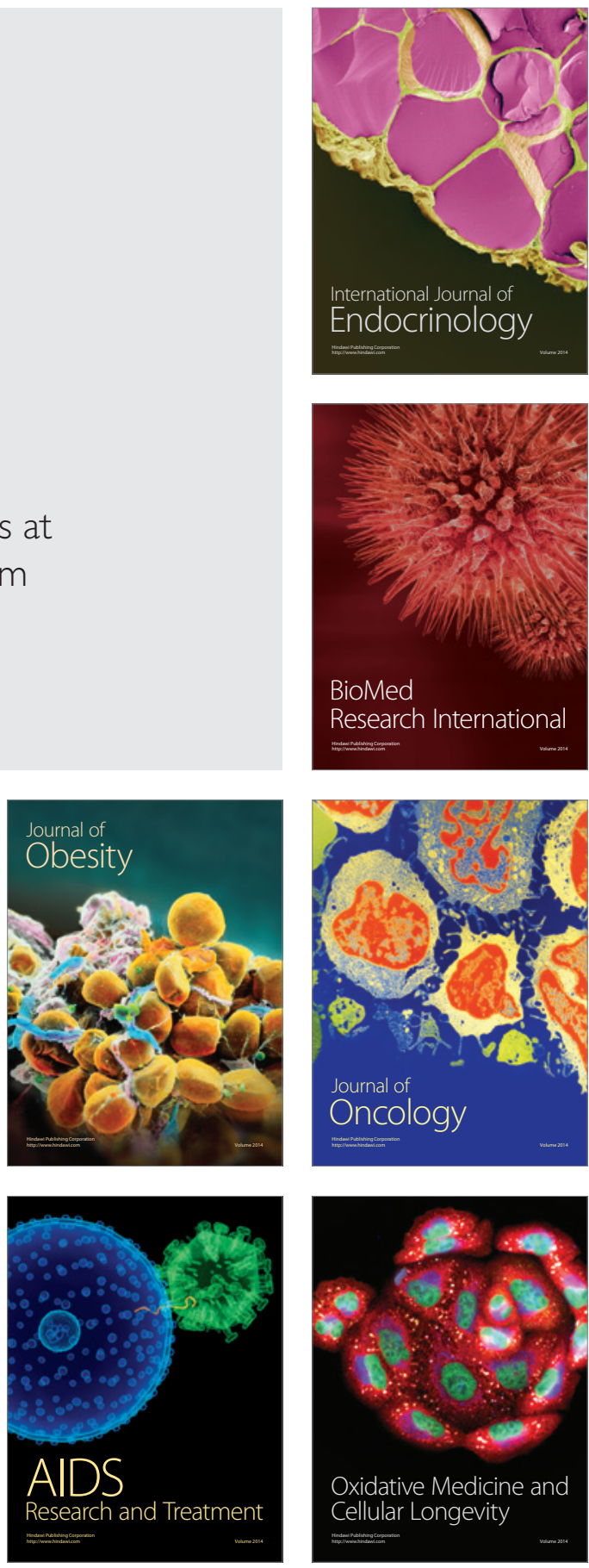